\title{
SERVIÇO DE REFERÊNCIA VIRTUAL: IMPLANTAÇÃO DO SERVIÇO DE CHAT
}

\author{
SERVICIO DE REFERENCIA VIRTUAL: IMPLEMENTACIÓN \\ DEL SERVICIO DE CHAT
}

\begin{abstract}
Natalia Nakano - natinakano@gmail.com Mestrando em Ciência da Informação pela Universidade Estadual Paulista (UNESP/Marília).
\end{abstract}

Maria José Vicentini Jorente - mijorente@yahoo.com.br Doutora em Ciência da Informação pela Universidade Estadual Paulista (UNESP/Marília).Docente do Departamento de Ciência da Informação da

UNESP/Marília.

\section{RESUMO}

Introdução: Com o advento da Internet e da Web Colaborativa, as bibliotecas tiveram que repensar a maneira como disponibilizam seus serviços. Assim, as bibliotecas norteamericanas iniciaram uma busca por inovações tecnológicas para levar a biblioteca até o usuário com recursos que ele já utiliza. O Serviço de Referência Virtual (SRV) por meio de chat online e a referência por videoconferência caracterizam serviços que derivaram dessa busca.

Objetivo: A proposta apresentada tem como objetivo delinear um dos processos de implantação dos recursos tecnológicos dos Serviços de Referência Virtuais (SRV) utilizados por bibliotecas de universidades norte-americanas, em especial aqueles para atendimento por chat, bem como apresentar as experiências brasileiras bem sucedidas. Propõe fatores a serem considerados para a implantação do Serviço de Referência Virtual por meio de chat para bibliotecas desejosas de incluir esse serviço de atendimento no rol de seus serviços.

Metodologia: A metodologia de pesquisa, consiste em um aporte teórico feito a partir da literatura produzida nacional e internacionalmente sobre o assunto, além de uma pesquisa exploratória realizada por meio da observação participante.

Resultados: O SRV é um serviço que traz benefícios à comunidade e coloca a biblioteca em consonância com as demandas tecnológicas de informação e comunicação.

Conclusões: Conclui-se que o SRV online em tempo real é apropriado à realidade das bibliotecas de universidades brasileiras, uma vez que as instituições que dispõem o serviço 
têm resultados positivos de suas avaliações e acreditam estar agregando valor à sua biblioteca.

Palavras-Chave: Serviço de referência virtual. Web. Biblioteca colaborativa. Chat. Skype. Informação e tecnologia.

\section{INTRODUÇÃO}

Com a popularização da internet tanto nos países desenvolvidos quanto nos países em desenvolvimento, e o advento da Web colaborativa, as bibliotecas universitárias tiveram que repensar a maneira como seus serviços são disponibilizados de forma a atingir seus usuários, em especial os nativos digitais (NAKANO; JORENTE, 2013).

Os serviços oferecidos pelas bibliotecas universitárias sempre foram ditados pela convergência de fatores como necessidade informacional dos alunos, suas características demográficas e habilidades tecnológicas. Isso se torna evidente quando se visita o site de uma biblioteca universitária, como por exemplo a da Universidade Estadual Paulista (UNESP) ou a da Universidade Estadual de Londrina (UEL), e se constatam os diferentes canais oferecidos para interagir e compartilhar com a instituição.

No início dos anos 2000, nos Estados Unidos, a biblioteca denominada 2.0 passou a oferecer Serviços de Referência Virtual (SRV) disponibilizando em seus sites, dentre outros serviços online, a possibilidade de se comunicar com 0 bibliotecário através de email e posteriormente de chats (ou bate-papo) em tempo real (NAKANO; JORENTE, 2013).

A proposta apresentada por este artigo tem como objetivo delinear um dos processos de implantação e implementação de recursos tecnológicos dos Serviços de Referência Virtual (SRV) utilizados por bibliotecas de universidades norteamericanas, em especial aqueles para atendimento por chat, bem como apresentar as experiências brasileiras bem sucedidas nesse sentido. De forma mais específica, propõe etapas para a implantação do Serviço de Referência Virtual por meio de chat para bibliotecas públicas ou privadas desejosas de incluírem esse serviço de atendimento no rol de seus serviços.

Nosso estudo nos Estados Unidos se fez por meio do software de mensagens instantâneas utilizado pelas bibliotecas norte-americanas de nome comercial Skype, 
que possibilita a videoconferência. Partimos da experiência relatada por Char Booth (2008) que motivou a implantação desse software em outras bibliotecas universitárias daquele país.

A experiência original de Referência Virtual com possibilidade de videoconferência utilizando o Skype relatada e implantada por Booth (2008) ocorreu na Universidade de Ohio. Booth (2008) desenvolveu um projeto piloto em 2007 no campus de Athens, que sozinho abriga aproximadamente 20.000 alunos. Considerando que a biblioteca deva estar em todos os lugares, um quiosque foi colocado em um andar distante do balcão de referência principal da universidade. Esse quiosque continha um computador, câmera e microfone, e o software gratuito Skype instalado onde era possível visualizar a bibliotecária na tela do computador em tempo real. Os usuários tinham, dessa maneira, a possibilidade de realizar consultas sem necessariamente ter que ir até o balcão principal da biblioteca.

O recurso de Chat Reference Service ou Serviço de Referencia através de bate-papo é um dos recursos disponibilizados gratuitamente pelo Skype e tema extensamente avaliado pela literatura internacional. Lou (2008) realizou um estudo de revisão de literatura analisando os artigos que tratam da avaliação do Chat Reference Service nos quais expôs todos os componentes e os resultados trazidos por esses artigos.

Um importante aspecto do trabalho dessa pesquisadora para o presente estudo diz respeito a maneira como os usuários percebem e usam o Serviço de Referência por meio de chat. Com relação ao conhecimento e preferências dos usuários, Lou (2008) reporta que os resultados diferem devido às diferentes populações pesquisadas. No entanto, em um estudo realizado por Johnson (2004) relatado por Lou (2008), o serviço de chat ficou em segundo lugar em preferência, perdendo apenas para o tradicional atendimento pessoal.

Outro aspecto importante relatado por Lou (2008, p. 79) é com relação à avaliação do usuário sobre o Serviço de Referência e às razões pelas quais os usuários (alunos e professores universitários) preferem o serviço online ao invés do atendimento personalizado. Os usuários na sua maioria relataram: "não queria ir até a biblioteca", "gosto de realizar outras tarefas enquanto espero pela resposta", "estava com pressa e esperava que o serviço fosse mais rápido", "precisava de uma resposta imediata". Essas razões claramente explicam que o usuário quer conveniência em termos de tempo e espaço. 
Ainda sob a perspectiva do usuário universitário, outro tema amplamente avaliado pela literatura é com relação à satisfação do usuário com o serviço de chat. Os trabalhos avaliaram a qualidade do serviço, o conhecimento do bibliotecário, a exatidão e o tempo da resposta, o fornecimento de referência apropriada e o horário de disponibilidade do serviço. Todos os artigos compilados por Lou (2008) apresentaram um alto nível de satisfação do usuário: entre 65 e 100\%.

Com relação à experiência da Universidade de Ohio com o Skype, depois de dois anos, Boeninger, o bibliotecário chefe do Serviço de Referência da Universidade de Ohio, anunciou em seu blog que o quiosque tinha sido desativado devido ao baixo índice de uso do recurso ${ }^{1}$. Essa informação corrobora várias observações participantes realizadas em universidades norte-americanas que utilizaram o Skype anteriormente e hoje decidiram por descontinuar o serviço.

Foi sugerido por Boeninger que o motivo pelo qual os usuários não apreciam realizar chamadas de vídeo com o bibliotecário é porque o usuário nativo digital é multitasker, ou seja, ele comumente se engaja em várias atividades ao mesmo tempo. O Bibliotecário Chefe afirma que na sua experiência com chat por texto, os usuários por vezes demoram a responder após o envio de uma mensagem, e ele não acredita que o usuário esteja ponderando a respeito da mensagem, mas sim que esteja engajado em outra tarefa, que pode variar desde checar seu Facebook a consultar um website recomendado.

Em contrapartida, observou-se que o Skype é utilizado na Ohio University especialmente por estudantes estrangeiros para conversar com seus pais, parentes e amigos no seu país de origem. Os bibliotecários universitários não tem esse tipo de relacionamento com os usuários, e portanto, uma outra hipótese levantada para o baixo uso do Skype para interação com bibliotecários é que os usuários apenas se dispõem a realizar ligações de vídeo com pessoas muito próximas, e podem nunca vir a se sentir confortáveis o suficiente com os bibliotecários das universidades.

Em observação participante por meio de Skype, verificou-se que a St. Edwards University no Texas, EUA, oferece o SRV por meio do Skype, porém o uso da videoconferência pelos estudantes é baixo se comparado ao chat por texto. Portanto, o uso desse recurso está sendo direcionado para propósitos educacionais tais como Webinars e treinamentos de pessoal.

${ }^{1}$ Booth (2010). 
Ainda que o uso do Skype tenha sido iniciado em várias universidades norteamericanas e depois descontinuado na maioria delas, a St. Edwards University não pretende cancelar o serviço. A Biblioteca afirma que o software traz benefícios: é gratuito, não exige treinamento de pessoal, tanto os bibliotecários quanto os usuários estão familiarizados com a interface, e acima de tudo, acredita que todos os esforços para aproximar os usuários dos bibliotecários são valiosos.

No Brasil, a experiência relatada acima com o software comercialmente conhecido como Skype não aconteceu, pois as implantações bem sucedidas em andamento com o SRV ocorreram mais recentemente e com o uso de outros software.

Em 2001, Márdero Arellano descreveu as principais iniciativas de SRV por meio de chat das bibliotecas universitárias norte-americanas e o serviço inovador que estava tomando forma naquela época - o consórcio de bibliotecas universitárias para oferecer Serviço de Referência por meio de chat 24 horas por dia, 7 dias por semana. Ele analisou os Serviços de Referencia Virtual, seus padrões e novas tecnologias que modificaram a prática tradicional do balcão de referencia nas bibliotecas daquele país.

Márdero Arellano (2001) ainda aponta que o SRV foi tema de muitos eventos da área e que a preocupação dos pesquisadores norte-americanos naquele momento era no sentido da institucionalização, criação de padrões técnicos e de qualidade, além do desenvolvimento de software que pudessem ser usados tanto nos serviços síncronos quanto assíncronos.

São várias e pertinentes as questões que permeiam a utilização de SRV com possibilidade de utilização de recurso de atendimento online em tempo real: seria o atendimento online em tempo real apropriado à realidade brasileira? Seria o contexto sociocultural brasileiro muito diferente do estrangeiro? As pessoas estão passando mais tempo nos seus computadores e buscando resolver suas necessidades informacionais por meio da Internet e nela a Web? A utilização de um software gratuito pelos centros de informação permitiria aos brasileiros que necessitam e buscam informações uma melhor e maior interação com o profissional da informação desses centros? Esse atendimento é um recurso que aproximaria os usuários brasileiros das bibliotecas, arquivos e museus? $\mathrm{O}$ atendimento presencial de referência difere do atendimento em ambiência digital? 
A partir de uma busca exploratória nos sites das bibliotecas universitárias brasileiras foi possível constatar que no território nacional poucas delas oferecem o Serviço de Referência Virtual tão comum e disseminado em países como os EUA. Nesse sentido, constatou-se em um estudo exploratório realizado por Pestana, Funaro e Ramos (2010) o seguinte resultado: $2 \%$ das bibliotecas da Universidade Estadual Paulista (UNESP) oferecem atendimento online, 5\% das bibliotecas da Universidade de São Paulo (USP) oferecem esse serviço e nenhuma biblioteca da Universidade de Campinas (UNICAMP) oferece atendimento online. Serviços como links, fale conosco e tutoriais são os mais comuns.

Estudos foram também realizados em outros estados brasileiros: na Paraíba duas bibliotecas estudadas não oferecem SRV, embora possuam páginas institucionais (NASCIMENTO et al., 2010); no Rio de Janeiro a Pontifícia Universidade Católica (PUC-Rio) oferece o serviço de atendimento online aos seus usuários desde 2002 encorajada por iniciativas internacionais (CARVALHO; MILMAN, 2008); no estudo de caso de Novak (2010), bibliotecas no Rio Grande do Sul, Brasília, Minas Gerais, Goiás e Rio de Janeiro responderam questões a respeito dos serviços de SRV oferecidos, mas somente a biblioteca do Rio de Janeiro, a PUC, mencionada no estudo de Carvalho e Milman (2008), oferece atendimento online. No estudo de Corrêa (2009), as 30 instituições de ensino superior do Brasil com maior número de alunos matriculados foram mapeadas e seus sites investigados: $3 \%$ oferecem serviço de atendimento online. Já no estudo de Vieira (2009), a biblioteca investigada de Natal, Rio Grande do Norte, possuía apenas serviço via telefone e correio eletrônico, não contando com SRV na época da pesquisa. No Paraná a Biblioteca Central da Universidade de Londrina passou a oferecer o Serviço de Referência Virtual por meio de chat em setembro de 2011 (LETRARI, ZWARETCH, ZANINELI, 2012). Atualmente a UNICAMP oferece 0 atendimento por meio de chat na Biblioteca da Área de Engenharia e Arquitetura (FERREIRA et al., 2012).

A universidade brasileira pioneira na implantação de serviços de referência virtual por meio de chat com mensagens síncronas foi a Pontifícia Universidade Católica do Rio de Janeiro (CARVALHO; MILMAN, 2008). Na avaliação descrita por Carvalho e Milman, concluiu-se que embora o serviço esteja disponibilizado aos usuários da biblioteca da PUC-Rio há alguns anos, ainda existe uma preferência pelo atendimento por e-mail e por telefone. 
A experiência relatada por quatro bibliotecas da USP que implantaram o serviço de atendimento online, ou Chat Reference Service, foi positiva. Os argumentos principais foram: 1) os Serviços de Referência (SR) tem que estar em consonância com a demanda dos usuários, 2) as novas Tecnologias de Informação e Comunicação (TIC) possibilitam a disponibilização do serviço, 3) os software livres e gratuitos são considerados de interface amigável e são amplamente disseminados entre a população acadêmica, 4) 0 atendimento tradicionalmente feito por telefone pode custar caro, dependendo da localidade do usuário, 5) o uso do correio eletrônico não é síncrono, podendo não atender à necessidade do usuário com relação à rapidez da resposta, considerando o caráter dinâmico da informação, 6) os serviços baseados nas tecnologias de comunicação exigem esforços adicionais para a manutenção de qualidade resultando em ganhos para a comunidade (SANTANA et al., 2010).

Esse artigo pretende discutir as experiências com a implantação do SRV em bibliotecas nacional e internacionalmente para que as bibliotecas brasileiras desejosas ou que estejam considerando a implantação do Serviço de Referência Virtual por meio de chat possam se beneficiar de um leque mais amplo de experiências, e dessa forma economizar tempo, esforço e ansiedade com dificuldades que outras instituições já superaram.

\section{METODOLOGIA}

A metodologia de pesquisa consiste em um aporte teórico feito a partir da literatura produzida nacional e internacionalmente sobre o assunto, além de pesquisa exploratória realizada por meio da observação participante, na qual o observador/pesquisador é parte dos eventos que estão sendo pesquisados.

Tal metodologia científica é apropriada para essa pesquisa, pois apresenta vantagens como a percepção de acontecimentos que não seria possível a um observador estranho, e permite não apenas a observação de comportamentos, mas também de atitudes, opiniões e sentimentos (VIANNA, 2003, p. 50). Além disso, possibilita uma interação informal entre o pesquisador e as pessoas que integram 0 ambiente observado com compartilhamento de informações, impossível senão por esse meio. 
A observação participante em território nacional foi aprovada pelo Comitê de Ética da Universidade Estadual Paulista Júlio de Mesquita Filho - UNESP de Marília, sob o número 2013/636. A observação dos trabalhos dos bibliotecários de referência se deu presencialmente na Biblioteca Central da Universidade Estadual de Londrina. As observações participantes com bibliotecários norte-americanos se deram virtualmente por meio do Skype ou por meio de chat. Nessas observações a pesquisadora assumiu o papel de usuária do serviço realizando questionamentos de referência.

\section{FATORES DE IMPLANTAÇÃO DO SRV}

Os fatores que devem ser considerados ao decidir sobre a disponibilização do serviço, seguindo a observação realizada na UEL, e as orientações da RUSA (Reference \& User Services Association) para Implementação e Manutenção de Serviços de Referência Virtual²:

\subsection{O Profissional da Informação}

Os bibliotecários de referência devem entender a necessidade da implantação do serviço no sentido de acompanhar a demanda do usuário que hoje conta com os serviços disponibilizados por meio da Internet. Dessa forma agrega-se mais valor aos serviços oferecidos pela biblioteca. É um equívoco acreditar que o serviço por chat sobrecarregará os bibliotecários ou bibliotecas que às vezes pode contar apenas com poucos profissionais. A experiência desse estudo encontrou que os atendimentos por chat levam cerca de 5 a 10 minutos, enquanto que um atendimento no balcão pode se prolongar por muito mais tempo.

\subsection{A Escolha do Software}

Atualmente existem diversos software disponíveis gratuitamente no mercado, porém é necessário que o escolhido atenda às necessidades da biblioteca quanto a compatibilidade com o sistema da universidade, quando ao número de usuários e ao número de bibliotecários que estarão trabalhando no atendimento. Por exemplo, o

\footnotetext{
${ }^{2}$ Reference and User Services Association (2010).
} 
software Skype, embora tenha uma interface amigável e seja familiar para os usuários pode não ser uma boa escolha dependendo do número de usuários da biblioteca, pois ele demanda que a biblioteca adicione o usuário em um lista de contatos, e essa lista pode ficar impraticável se o número de usuários da universidade for muito grande.

A PUC do Rio, pioneira na disponibilização do Serviço de Referência online por meio de chat iniciou o serviço em 2002 restrito aos usuários da comunidade da PUC-Rio como alunos, professores, funcionários e ex-alunos cadastrados na biblioteca. Atualmente, a biblioteca também atende visitantes. A princípio, a biblioteca implantou o software PhpMyChat para o atendimento do SRV (CARVALHO; MILMAN, 2008). Atualmente, o software utilizado é o Crafty Syntax ${ }^{3}$.

A Figura 1 mostra a interface da página da Biblioteca da PUC-Rio em que o serviço está disponibilizado tanto para comunidade interna quanto para Visitantes.

Figura 1 - Página da Biblioteca PUC-Rio

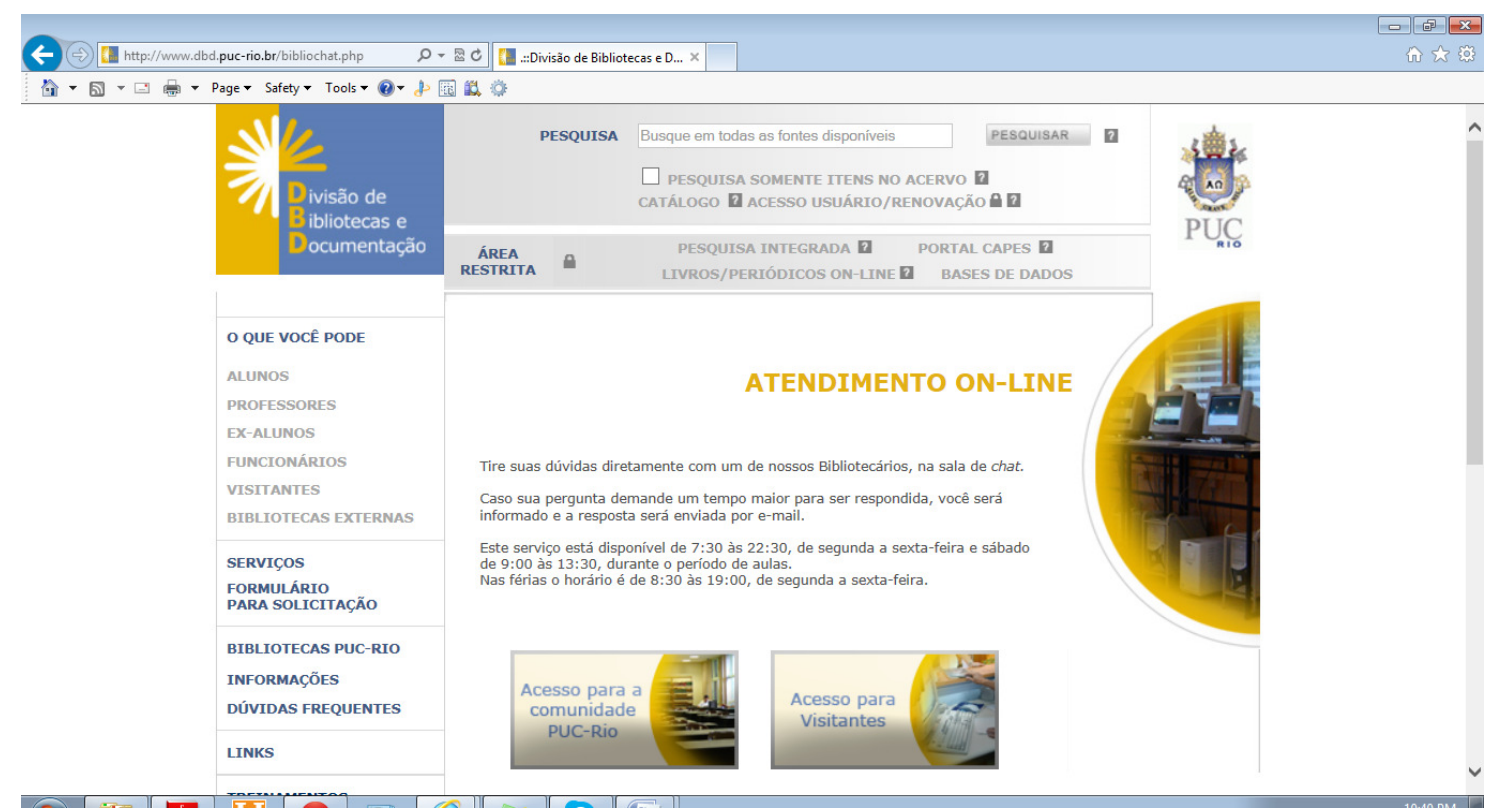

Fonte: Pontifícia Universidade Católica do Rio de Janeiro (2013).

A Figura 2 mostra a interface usuário/visitante. É possível deixar uma mensagem para o bibliotecário caso o atendimento por chat não esteja disponível escolhendo a aba "Contato Off-line".

${ }^{3}$ Link: http://www.craftysyntax.com. 
Figura 2 - Interface usuário visitante do atendimento por chat da PUC-Rio.

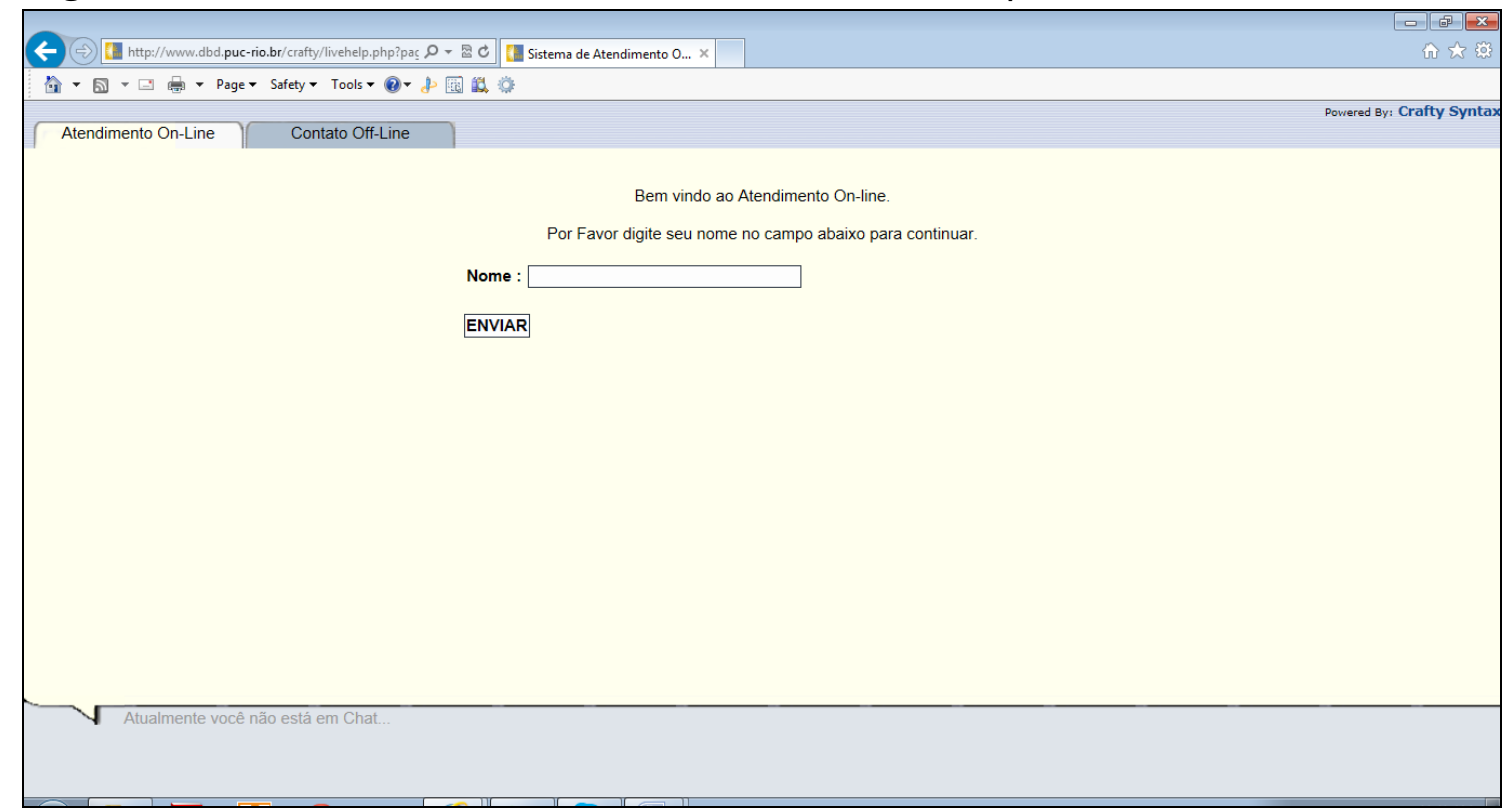

Fonte: Pontifícia Universidade Católica do Rio de Janeiro (2013)

A experiência das bibliotecas da USP que disponibilizam o SRV foi relatada por Santana et. al. em 2010. Em 2009, a Biblioteca da Faculdade de Medicina Veterinária e Zootecnia (FMVZ) implantou o Serviço de Referência por meio de chat online, e nos meses subsequentes outras quatro bibliotecas da USP convergiram para a experiência: a Escola de Engenharia de São Carlos (EESC), em setembro de 2009; o Instituto de Física de São Carlos (IFSC) e o Instituto de Psicologia (IP) em outubro de 2009; e a Faculdade de Odontologia (FO) em dezembro de 2009.

De acordo com os autores, a Biblioteca da FMVZ/USP analisou diversos software de atendimento ou suporte online disponíveis no mercado até decidir pela escolha do software LiveZilla. "A seleção do LiveZilla se deu pela possibilidade de customização e por sua interface de atendimento não utilizar navegador web, mas sim uma interface desktop." (SANTANA et al., 2010, p. 6). Além de recursos para customização, algumas das características do software permitem organizar vários atendentes online bem como recursos visuais e sonoros para alertar quando há uma resposta tanto para o atendente bibliotecário quanto para o usuário do SRV.

A Figura 3 mostra a interface para a qual o usuário é direcionado quando "atendimento online" é clicado na página da biblioteca. 
Figura 3 - Interface usuário do chat da Faculdade de Medicina Veterinária e Zootecnia da USP.

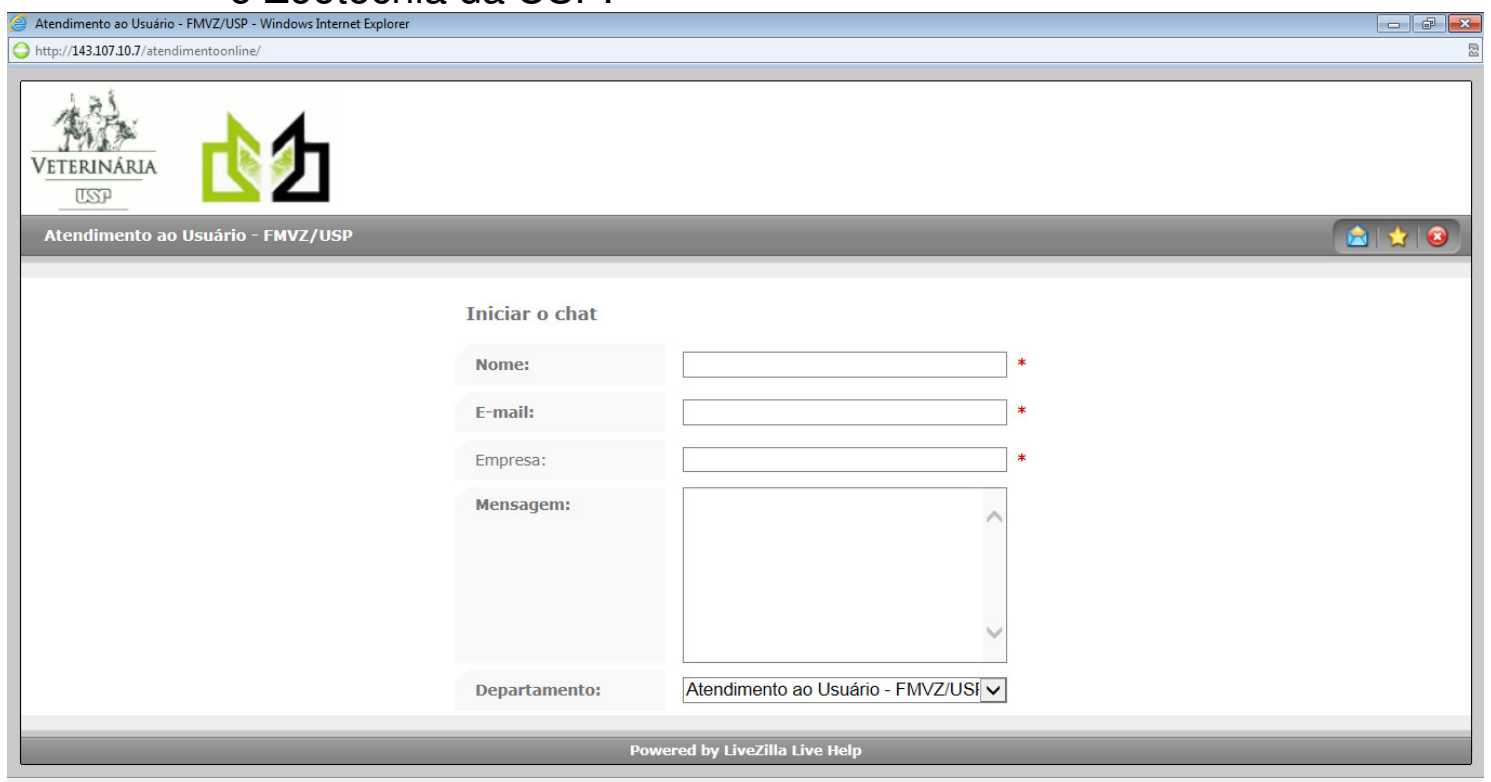

Fonte: Faculdade de Medicina Veterinária e Zootecnia da USP (2013).

A empresa LiveZilla $\mathrm{GmbH}$ foi fundada em junho de 2009 na Alemanha por Kevin Spaun. O software LiveZilla não foi primariamente desenhado para bibliotecas, foi criado para sites de empresas privadas com a finalidade de possibilitar atendimento online para seus clientes e para registrar os visitantes de seu site. No Brasil, a experiência bem sucedida de Santana (2010) com o software LiveZilla ${ }^{4}$ levou a Universidade Estadual de Londrina, a UEL, a estudar e posteriormente implantar o software para o seu atendimento por chat em tempo real.

Quando a Biblioteca Central da UEL decidiu pela implantação do Serviço de Referência Virtual por meio de chat, motivada primeiramente pelo desempenho dos seus profissionais atualizados com as tendências internacionais no sentido de acompanhar o dinamismo e interatividade que as novas tecnologias de comunicação e informação propiciam, tinha-se em mente que o software deveria ser gratuito e de interface amigável.

A UEL inicialmente considerou utilizar o MSN da Microsoft, e de fato chegou a instalar o software para pré-testes. Porém, uma série de pontos foram avaliados como negativos:

- o MSN requer que o usuário seja adicionado em uma lista de contatos e isso foi avaliado como um ponto negativo, pois a lista de contatos pode ficar enorme dependendo do número de usuários e atendimentos;

\footnotetext{
${ }^{4}$ https://www.livezilla.net/home/en.
} 
- um segundo ponto foi percebido no pré-teste realizado com o MSN nos cinco computadores e os bibliotecários de referência ligados ao mesmo tempo (a UEL conta com cinco bibliotecários de referência na Biblioteca Central): o desempenho foi insatisfatório pois um computador derrubou o serviço do outro;

- um terceiro ponto avaliado como negativo foi a fragmentação do histórico gerado pelo MSN: estar armazenado em diferentes computadores dificultaria as posteriores avaliações e estatísticas do serviço.

- Por outro lado, no pré-teste com o LiveZilla, foram avaliados como pontos positivos:

- a interface é bem simples e amigável tanto para o usuário quando para o administrador, no caso os bibliotecários. A questão colocada pelo usuário na caixa "Your Question" é imediatamente direcionada para o Bibliotecário de Referência. Essa ação constitui toda a complexidade do processo. Quando a pergunta chega ao computador que está configurado como servidor, esse a direciona aos 5 atendentes.

- $\mathrm{Na}$ interface do administrador, os roteiros de conversas entre 0 bibliotecário e o usuário (scripts) nas consultas ficam registradas, bem como os IPs (Protocolos de Identificação) dos computadores dos usuários. Nesse processo, fica explicitado, por exemplo, se o usuário é da UEL ou visitante.

- o Livezilla também deixa registrado quem realizou o atendimento e caso o serviço esteja offline, é possível que o usuário deixe uma mensagem.

A partir do registro desses scripts, foi possível analisar que tipo de perguntas os usuários fazem à bibliotecária por meio do chat. Uma vez que a utilização não foi muito grande na época daquela avaliação, as bibliotecárias geraram relatórios de análise dessas perguntas manualmente. Nessa primeira avaliação, a maioria dos questionamentos referia-se a empréstimos e renovações de livros; embora exista 0 tutorial que responde a essas questões, os usuários parecem necessitar da reafirmação do bibliotecário.

Com base nos resultados do pré-teste, a Biblioteca Central decidiu pela implantação definitiva do software LiveZilla conjuntamente com a Assessoria de 
Tecnologia de Informação da Universidade, que aprovou esse software por ser compatível com o sistema da UEL.

\subsection{Decidir se o Serviço será Centralizado ou Descentralizado}

$\mathrm{Na}$ experiência da Universidade Estadual de Londrina, foi decidido que em um primeiro momento, a Biblioteca Central realizaria todos os atendimentos, porém a descentralização para incluir as bibliotecas setoriais não seria descartada, dependendo dos questionamentos dos usuários e volume de consultas.

\subsection{Realização de Testes e Treinamento de Pessoal}

Uma vez que o software foi escolhido, é importante que testes sejam realizados com os usuários e uma padronização do atendimento seja concordada. Informar na página da biblioteca que o serviço está em fase de testes e encorajar os usuários a deixarem sugestões ou reclamações no final do atendimento pode ser uma boa prática. Com relação à padronização do serviço, ele deve se focar na linguagem e no comportamento do profissional da informação, uma vez que a interface administrativa do software, assim como a interface do usuário deva ser simples e amigável e portanto não consuma muito tempo e esforço.

Com relação à linguagem utilizada pelos bibliotecários no atendimento virtual, foram encontradas duas posições:

- os bibliotecários de referência da UEL concordaram que a linguagem deve ser formal, evitando gírias e contrações, por exemplo "vc" não deve ser usado como substituto de "você". Também concordaram que o usuário de chat não deve, em hipótese alguma, ser confundido com um colega com quem o profissional interage por chat, ou seja, o usuário de Referência por chat deve ser tratado da mesma maneira que o usuário de balcão. As práticas de referência presenciais são repetidas virtualmente. A mesma posição foi adotada pelas bibliotecas da USP:

Os atendentes foram capacitados no uso da ferramenta e foram criadas mensagens padronizadas para o atendimento, permitindo maior agilidade e qualidade nas respostas aos usuários, evitando erros de digitação e uso de termos coloquiais (SANTANA, 2010, p. 8, grifo nosso). 
- para as bibliotecas nos Estados Unidos a orientação da RUSA (Reference and User Services Association), é no sentido de ser informal, amigável e polido para motivar uma aproximação com um usuário ${ }^{5}$.

Uma questão levantada pela UEL que deveria ser discutida pela comunidade científica, é com relação a orientação para os profissionais da informação no momento da interação com os usuários no ambiente digital. A literatura existente é desatualizada e não dispõe sobre o perfil do profissional, suas qualidades pessoais, e como deve ser seu comportamento durante $o$ atendimento virtual. Essa deficiência foi percebida pelos profissionais da Biblioteca Central da UEL pois o serviço ainda não está padronizado ou institucionalizado no Brasil, como mencionado por Márdeo Arellano (2001) sendo a preocupação dos profissionais da informação naquela época nos Estados Unidos.

Fora do Brasil, a RUSA e outras organizações institucionalizaram e padronizaram sugestões para um melhor desempenho do profissional da informação com a publicação das Diretrizes para o Desempenho Comportamental do Fornecedor de Serviços de Informação e Referência (Guidelines for Behavioral Performance of Reference and Information Service Providers) revista e aprovada em $2004^{6}$.

As diretrizes levam em consideração que em todas as formas de referência (tanto presencialmente no balcão quanto virtualmente, por chat online, e-mail ou telefone, etc. quando as tradicionais informações visuais e não verbais são inexistentes) o sucesso da consulta de referência não é somente medido pela precisão da informação fornecida, mas pelo impacto positivo ou negativo que o profissional causa no usuário.

As cinco áreas cobertas por essas diretrizes compreendem a maneira de abordar um usuário, como demonstrar interesse na sua necessidade informacional, como saber ouvir e questionar o usuário de forma a entender exatamente o seu objetivo, o processo de busca pela informação, e finalmente o acompanhamento do atendimento.

\footnotetext{
${ }^{5}$ Question Point (2013).

${ }^{6}$ Reference and User Services Association (2013).
} 
Nesse mesmo contexto, as autoras Connaway e Radford apresentaram em 2011 o relatório final do projeto Buscando Sincronicidade: Avaliando o serviço de referencia virtual a partir das perspectivas dos usuários, não-usuários e bibliotecários, financiado pelo Instituto de Museu e Serviços de Biblioteca da Rutgers, Universidade Estadual de Nova Jersey (The State University of New Jersey) e OCLC Online Computer Library Center, Inc. A pesquisa consistiu em quatro fases de coleta de dados e análises, de outubro de 2005 a março de 2008, e teve como objetivo principal disponibilizar recomendações baseadas em uma pesquisa que melhore de forma geral o SRV fornecido por profissionais da informação.

Na mesma linha de Boeninger, o primeiro achado de Connaway e Radford é no sentido de que o "R" no SRV dever se transformar em "R" de Relacionamento, a fim de ser um serviço bem sucedido. As autoras afirmam que para que as pessoas aceitem e promovam o papel dos serviços informacionais virtuais da biblioteca nas suas vidas, o "R" tem que ser também de relacionamento, pois a comunicação interpessoal é vital para satisfação e sucesso tanto para o usuário quanto para o bibliotecário: ' $O$ ' $R$ ' na referência virtual tem que mudar se as bibliotecas quiserem ser bem sucedidas em promover a referência por meio de chats, telefonemas, $e$ mails, mensagens de textos, dispositivos móveis ou outros objetos tecnológicos ainda não imaginados." (CONNAWAY; RADFORD, 2011, p. 2).

Sabe-se que a melhor forma de se cativar um usuário de referência por uma vida é durante a entrevista pessoal, portanto, a sugestão de Connaway e Radford (2011) é que os bibliotecários apresentem o SRV quando o usuário estiver presente na biblioteca. Sem uma introdução explícita ao SRV, muitos usuários não trarão a confiança e apreço que eles sentem pelos bibliotecários para uma experiência online.

Outro achado da pesquisa foi que o desenvolvimento de relacionamento está ligado a cortesia, logo é recomendado não ignorar pequenos "gestos" quando se trata de conversas virtuais, até mesmo um "obrigado" ou "por favor aguarde", que pode ser gerada automaticamente, é significativo. Manter um serviço profissional, e ao mesmo tempo amigável constrói um bom relacionamento e evita situações difíceis. 


\subsection{Divulgação do Serviço de Atendimento por Chat}

De acordo com o relatório de Connaway e Radford (2011), a divulgação do serviço deve se dar nos momentos presenciais, ou seja, nos momentos de atendimento pessoal e nos treinamentos. As autoras também enfatizam que a divulgação em forma de cartazes e banners deve estar no ambiente da biblioteca, e que deve se dar de forma contínua - não se deve presumir que o usuário lembrará de utilizar o chat quando necessitar de informação se ele não estiver familiarizado com o serviço. Assim como as empresas de marketing procuram impregnar a imagem da marca, a biblioteca deve reforçar a existência do serviço para que quando o usuário pense na biblioteca, o chat venha a sua mente.

A Biblioteca Central da UEL realizou no momento da implantação do serviço, e ainda realiza periódica e continuamente, divulgação do SRV nos treinamentos para alunos e profissionais, bom como notas no Facebook, jornal da UEL, e lista de discussões.

\subsection{Avaliação do Serviço}

De acordo com as Diretrizes para Implementação e Manutenção de Serviços de Referência Virtual da RUSA, a avaliação da eficiência e eficácia do SRV deve se realizar regularmente por feedback dos funcionários e dos usuários a fim de oferecer um serviço de qualidade. Deve compreender diferentes métodos, tais como a análise de estatística de uso, sugestões e reclamações de usuários e revisões de roteiros de entrevistas (scritps). A primeira avaliação realizada pela UEL relatada em 2012 verificou as questões mais solicitadas e as dúvidas dos usuários (LETRARI; ZWARETCH; ZANINELI, 2012).

\section{CONSIDERAÇÕES FINAIS}

O SRV por meio de chat está sedimentado nos EUA - com uma busca exploratória na Internet por sites de bibliotecas de universidades é possível afirmar que o serviço está implantado em muitas delas; o SRV também se encontra padronizado e institucionalizado pelas organizações americanas representativas da comunidade da informação, como a RUSA (Reference and User Services Association) e a ALA (American Library Association). 
No Brasil sua implantação conta com algumas universidades, e de acordo com essas, o SRV é um serviço que traz benefícios à comunidade e coloca a Biblioteca em consonância com as demandas tecnológicas de informação e comunicação.

Oferecer um serviço de referência virtual por Chat em uma biblioteca universitária é um desafio, mas que vale a pena o empenho e o investimento, principalmente pelas vantagens que apresentam, tanto para o usuário como para a biblioteca, como a imediatez da resposta, evitando a demora de informação para o usuário e atendimento na hora de sua necessidade (LETRARI; ZWARETCH; ZANINELI, 2012, p. 7).

$\mathrm{Na}$ experiência da observação participante na UEL, por exemplo, as bibliotecárias relataram acreditar que a disponibilização do serviço é válida principalmente quando o atendimento é realizado a ex-alunos da universidade que se encontram em outras cidades; ou alunos de pós-graduação que utilizam o serviço estando na sua cidade de origem sem terem que realizar uma ligação à longa distância. Em ambos os casos, os usuários têm sua necessidade informacional resolvida por um profissional da informação que está à disposição na biblioteca. Percebe-se que dessa maneira o SRV aproximou os usuários da biblioteca e possibilitou uma interação de qualidade com o profissional da informação, livre do custo de uma ligação telefônica ou o tempo de espera de um e-mail.

Embora a preferência dos usuários da Biblioteca Central da UEL ainda seja em utilizar o e-mail e o telefone para contatar a biblioteca, acredita-se que com o tempo os usuários mais familiarizados com a disponibilização do serviço e, portanto, a sua conveniência, utilizarão o chat com mais frequência.

Em consonância, na pesquisa de Connaway e Radford, quando se perguntou aos usuários como os bibliotecários poderiam convencer os não-usuários a utilizar um serviço de referência por chat, o fator citado foi a percepção da conveniência do serviço (CONNAWAY; RADFORD, 2011).

Com relação ao atendimento presencial diferir do atendimento em ambiência digital, o relatório de Connaway e Radford (2011) menciona que como algumas percepções facilmente captadas no relacionamento pessoal estão ausentes no relacionamento virtual, torna-se vital que o profissional da informação realize questionamentos de referência para esclarecer exatamente qual o objetivo do usuário para se obter um resultado satisfatório. 
De forma geral, o relatório conclui que para disponibilizar um serviço de qualidade, há poucos fatores que tendem a tornar qualquer consulta de referência virtual bem sucedida: precisão nas respostas, postura positiva por parte da bibliotecário e boas habilidades de comunicação. Além desses fatores, é importante que o profissional da informação seja agradável, otimista, e esclareça o usuário sobre o que o bibliotecário pode fazer por ele, ao invés daquilo que não pode.

A partir dos resultados dessa pesquisa, conclui-se que o SRV online em tempo real é apropriado à realidade das bibliotecas de universidades brasileiras, uma vez que as instituições que dispõem o serviço têm resultados positivos de suas avaliações e acreditam estar agregando valor à sua biblioteca.

Nossos agradecimentos à Maria Elisabete Catarino, Neide Maria Jardinette Zanineli, Maria Aparecida dos Santos Letrari, e Natali Silvana Zwaretch, profissionais da informação da Biblioteca Central da UEL, que contribuíram de maneira inestimável para essa pesquisa.

\section{REFERÊNCIAS}

BOOTH, Char. Developing skype-based reference services. Internet Reference Services Quarterly, New York, v. 13, n. 2-3, p. 147-165, 2008. Disponível: <http://dx.doi.org/10.1080/10875300802103684>. Acesso em: 5 jan. 2012.

So maybe this is why no one uses our skype reference service. 2010.

Disponível em: <http://libraryvoice.com/technology/so-maybe-this-is-why-no-oneuses-our-skype-reference-service>. Acesso em: 11 maio 2013.

CARVALHO, Pâmela Lisboa de; MILMAN, Sandra Mendes. Atendimento ao usuário através de chat: a experiência da biblioteca da PUC-RIO. In: SEMINÁRIO NACIONAL DE BIBLIOTECAS UNIVERSITÁRIAS, 15., 2008, São Paulo. Anais... São Paulo: CRUESP, 2008. Disponível em:

<http://www.sbu.unicamp.br/snbu2008/anais/site/pdfs/2841.pdf>. Acesso em: 30 abr. 2012.

CONNAWAY, Lynn. Silipigni; RADFORD, Marie L. Seeking synchronicity: revelations and recommendations for virtual reference. Dublin, OH: OCLC Research, 2011. Disponível em: <http://www.oclc.org/reports/synchronicity/default.htm>. Acesso em: 8 jun. 2013.

CORRÊA, Elaine. $O$ serviço de referencia virtual em bibliotecas universitárias com ênfase na interação bibliotecário/usuário: pergunte ao bibliotecário. 2009. 40 f. Monografia (Especialização em Gestão de bibliotecas e comunicação) Universidade Federal do Rio Grande do Sul, Porto Alegre, 2009. Disponível em: <http://www.lume.ufrgs.br/handle/10183/18483 >. Acesso em: 19 maio 2012. 
FACULDADE DE MEDICINA VETERINÁRIA E ZOOTECNIA DA USP. Biblioteca Virtual em Medicina Veterinária e Zootecnia. Atendimento online. Disponível em: <http://www.bvs-vet.org.br/php/index.php>. Acesso em: 8 jun. 2013.

FERREIRA, Danielle T. et al. Serviço de atendimento on-line por chat: experiência da biblioteca da área de engenharia e arquitetura da Unicamp. In: SEMINARIO NACIONAL DE BIBLIOTECAS UNIVERSITÁRIAS, 17., 2012, Gramado. Anais... Rio Grande do Sul, 2012.

LETRARI, Maria Aparecida dos Santos; ZWARETCH, Natali Silvana; ZANINELI, Neide Jardinette. Atendimento online por meio do chat: um serviço de referência 2.0 da Biblioteca Central da UEL. In: SEMINARIO NACIONAL DE BIBLIOTECAS UNIVERSITÁRIAS, 17., 2012, Gramado. Anais... Rio Grande do Sul, 2012.

LIVE!ZILLA. Disponível em: <https://www.livezilla.net/home/en/>. Acesso em $31 / 05 / 2013$.

LOU, Lili. Chat reference evaluation: a framework of perspectives and measures. Reference Services Review, Ann Arbor, v. 36, n. 1, p.71-85, 2008. Disponível: <http://dx.doi.org/10.1108/00907320810852041>. Acesso em: 05 jan. 2012.

MÁRDERO ARELLANO, Miguel Ángel. Serviços de referência virtual. Ciência da Informação, Brasília, v. 30, n. 2, p. 7-15, 2001. Disponível em: <http://www.scielo.br/pdf/ci/v30n2/6206.pdf>. Acesso em: 25 out. 2012.

NAKANO, Natalia; JORENTE, Maria Jose V. Serviço de referência virtual: uma análise do serviço de referência síncrono disponibilizado por bibliotecas de universidades brasileiras. In: SEMINARIO CIENTÍFICO ARQUIVOLOGIA E BIBLIOTECONOMIA: Acesso à Informação, 3., 2013, Marília. Anais... Marília: UNESP, 2013.

NASCIMENTO, José Carlos Júnior Nóbrega do et al. Serviço de referência nas bibliotecas universitárias na cidade de João Pessoa/PB: a prática do bibliotecário diante das tecnologias. In: ENCONTRO NACIONAL DE ESTUDANTES DE BIBLIOTECONOMIA, DOCUMENTAÇÃO, GESTÃO, E CIÊNCIA DA INFORMAÇÃO, 33., 2010, João Pessoa. Anais... João Pessoa: UFPB, 2010. Disponível em: <http://dci.ccsa.ufpb.br/enebd/index.php/enebd/article/view/134>. Acesso em: 20 abr. 2012.

NOVAK, Loiva Duarte. Bibliotecas universitárias e o serviço de referencia virtual: parceria a favor do usuário. 2010. 66 f. Trabalho de Conclusão de Curso (Graduação em Biblioteconomia) - Biblioteconomia e Comunicação, Universidade Federal do Rio Grande do Sul, Porto Alegre, 2010. Disponível em: <http://www.lume.ufrgs.br/handle/10183/27799>. Acesso em: 30 abr. 2012.

PESTANA, Maria Cláudia; FUNARO, Vânia Martins Bueno de Oliveira; RAMOS, Lúcia Maria Sebastiana Verônica Costa. Análise das ferramentas web disponibilizadas pelas bibliotecas da USP, UNESP e UNICAMP. In: SEMINÁRIO NACIONAL DE BIBLIOTECAS UNIVERSITÁRIAS, 16., 2010, Rio de Janeiro.

Trabalhos... Rio de Janeiro: UFRJ, 2010. Disponível em: <http://www.gapcongressos.com.br/eventos/z0070/trabalhos/final_043.pdf>. Acesso em: 21 jun. 2012. 
PONTIFÍCIA UNIVERSIDADE CATÓLICA DO RIO DE JANEIRO - PUC-Rio. Divisão de Bibliotecas e Documentação. Atendimento on-line. Disponível em: <http://www.dbd.puc-rio.br/bibliochat.php>. Acesso em: 8 jun. 2013.

QUESTIONPOINT. Best practices for 24/7 reference cooperative sessions. Disponível em: <http://wiki.questionpoint.org/w/page/13839421/247-Best-Practices>. Acesso em 08/06/2013.

REFERENCE AND USER SERVICES ASSOCIATION. Guidelines for implementing and maintaining virtual reference services. 2010. Disponível em: $<$ http://www.ala.org/rusa/sites/ala.org.rusa/files/content/resources/guidelines/virtualreference-se.pdf>. Acesso em: 8 jun. 2013.

Guidelines for behavioral performance of reference and information service providers. 2013. Disponível em:

<http://www.ala.org/rusa/resources/guidelines/guidelinesbehavioral>. Acesso em: 08/06/2013.

SANTANA, Anderson et al. Atendimento online em bibliotecas: a experiência da universidade de São Paulo. In: SEMINÁRIO NACIONAL DE BIBLIOTECAS UNIVERSITÁRIAS, 16., 2010, Rio de Janeiro. Trabalhos... Rio de Janeiro: UFRJ, 2010. Disponível em:

<http://www.gapcongressos.com.br/eventos/z0070/trabalhos/final_225.pdf>. Acesso em: 30 abr. 2012.

VIANNA, Heraldo Maecelim. Pesquisa em educação: a observação. Brasília: Plano, 2003.

VIEIRA, Danyelle Paz. Serviço de referência virtual da biblioteca central Zila Mamede. 2009. 48 f. Trabalho de Conclusão de Curso (Graduação em Biblioteconomia) - Centro de Ciências Sociais Aplicadas, Universidade Federal do Rio Grande do Norte, Natal, 2009. Disponível em: <http://repositorio.ufrn.br:8080/monografias/bitstream/1/96/1/DanyellePV_Monografia. pdf>. Acesso em: 21 jun. 2012.

\section{Title}

Virtual reference service: implementing the chat service

\section{Abstract}

Introduction: With the invention of the Internet and the Collaborative Web, libraries had to rethink the way to offer their services. Thus, the U.S. libraries began a search for technological innovations in an effort to bring the library to the user through features that patrons commonly use. The Virtual Reference Service (VRS) through chat and reference services via videoconferencing are features that derived from this search.

Objective: This article aims to outline the implementation process of Virtual Reference Services (SRV) libraries in American universities, particularly those for chat, as well as 
presenting the successful Brazilian experience. This paper also discusses factors to be considered for implementing virtual reference service via chat for libraries wishing to offer the service.

Methodology: The research methodology is based on a theoretical search on international and national literature on the subject. The methodology also includes participant observation. Results: In Brazil the implementation of SRV in some university libraries has occurred and according to these institutions, the SRV is a service that benefits the community and puts the library in line with the demands of information technology and communication.

Conclusions: It is concluded that online SRV is appropriate to the reality of university libraries in Brazil, since the institutions that offer the service have positive results from their assessments and believe they are adding value to their library.

Keywords: Virtual reference service. Web. Collaborative library. Chat. Skype. Information and technology.

\section{Titulo}

Servicio de referencia virtual: implementación del servicio de chat

\section{Resumen}

Introducción: Con el advenimiento de la Internet y la Web Colaborativa, las bibliotecas han tenido que replantear la forma en que prestan sus servicios. Por lo tanto, las bibliotecas norteamericanas comenzaron la búsqueda de innovaciones tecnológicas para traer la biblioteca al usuario a través de funciones que utilizan. El Servicio de Referencia Virtual (SRV) a través de los servicios de referencia de chat y videoconferencia son algunas de las funciones que derivan de esta búsqueda.

Objetivo: La propuesta pretende esbozar un proceso de implementación de recursos tecnológicos de los servicios de referencia virtual (SRV) de bibliotecas de universidades americanas, especialmente las que utilizan chat, así como presentar las experiencias brasileñas exitosas. Propondrá factores a ser considerados para implementar el servicio de referencia virtual a través de chat para las bibliotecas que deseen incluir este servicio.

Metodología: La metodología de la investigación, así como una contribución teórica a partir de la literatura se ha producido a nivel nacional e internacional sobre el tema, es el estudio llevado a cabo por medio de la observación participante.

Resultados: El SRV es un servicio que beneficia a la comunidad y pone la biblioteca en línea con las exigencias de tecnología de la información y la comunicación.

Conclusiones: Se concluye que el SRV en tiempo real es adecuado a la realidad de las bibliotecas universitarias en Brasil, ya que las instituciones que ofrecen el servicio tienen resultados positivos de sus evaluaciones y creen que agregan valor a su biblioteca.

Palabras Clave: Servicio de referencia virtual. Web. Biblioteca colaborativa. Chat. Skype. Información y tecnología.

Recebido em: 13.06 .2013

Aceito em: 11.02.2014

Inf. Inf., Londrina, v. 19, n. 1, p. 164 - 184, jan./abr. 2014. http:www.uel.br/revistas/informacao/ 